\title{
Analysis of Phosphorus, Potassium and Calcium Accumulation in Grape Leaves by Synchrotron Radiation X-Ray Fluorescence
}

\author{
Patsara Kimsamran $^{1}$, Sodchol Wonprasaid ${ }^{1}$, Somchi Tancharakorn ${ }^{2}$, and Waraporn Tantanuch ${ }^{2}$
}

\begin{abstract}
Grape (Vitis vinifera L.) requires 16 essential nutrients in balance quantity. When elements are deficient or imbalances, growth and yield will be significantly reduced. Nutrient deficiency in grape can be diagnosed by chemical analysis. However, it is time consuming technique and requires large amount of plant samples. Synchrotron radiation X-ray fluorescent (XRF) has been used to detect certain types of mineral nutrients in various materials. It is a fast technique and requires small amount of samples. The objectives of this research are to study plant nutrient status and to study the possibility of using the XRF for plant nutrient analysis in grape leaves. The experiment design was randomized complete block design (RCBD) with 3 replications. Seven methods of irrigation and fertilizer applications were applied to grape variety Marroo Seedless. Leaf nutrients including phosphorus, potassium and calcium were analyzed by chemical and synchrotron XRF technique. The results showed that, with the chemical analysis, phosphorus and potassium contents in the leaves of all treatments except control (no fertilizer application) were in the sufficient range. Leaves calcium content in most treatments were in the deficient range except treatments with calcium application. Synchrotron XRF analysis results showed similar trend as chemical analysis. The regression and correlation analysis indicated the significantly positive correlation of the plant nutrient contents between the synchrotron XRF technique and the chemical method $(\mathrm{R} 2=0.76,0.77$ and 0.90$)$. The results implied that the synchrotron XRF technique could be applied for nutrient analysis and the diagnosis of nutrient status in grape.
\end{abstract}

Keywords - Grape, Plant nutrients, Chemical analysis, XRF.

\section{INTRODUCTION}

G RAPEVINE is one of the important fruit crops in Thailand because of grape berries have high nutritional values and can be processed into several products. It also has high yield potential and good product prices which lead to the expansion of its growing areas. However, the suitable technologies for grape production under hot and humid conditions in Thailand are still limited, especially on nutrient and water management. Grape requires 16 essential mineral nutrients in suitable ratios for optimum growth. Its growth and yield will be limited if it receives an imbalance of mineral nutrients. In viticulture, nutrients deficiency can be diagnosed

\footnotetext{
${ }^{1}$ School of Crop Production Technology, Institute of Agriculture Technology, Suranaree University of Technology,Nakhon Ratchasima 30000 , Thailand.

${ }^{2}$ Synchrotron Light Research Institute (Public Organization), Nakhon Ratchasima 30000, Thailand.
}

by plant tissue chemical analysis. It is a powerful tool to determine nutrient disorders that may occur during the growing season. Synchrotron radiation $\mathrm{X}$-ray fluorescent technique (XRF) has been used to detect certain types of mineral nutrients in various materials. This technique required small amount of samples and is faster than chemical analysis. It can be applied to diagnose the level of nutrients in plants if its analysis results are significantly correlated with chemical analysis.

\section{A. Plant Nutrients Analysis}

Plant nutrients diagnosis and fertilizer requirement can be determined by 3 ways [1] 1.Observing visual symptoms, the symptoms are expressed on parts of the plant and can be seen most clearly from unusual leaves. 2. Soil analysis is primarily testing of soil fertility before planting. It is an important tool for assessing soil nutrient availability to proper fertilizer recommendations and for diagnosing specific cropping problems. 3. Plant analysis is a testing of nutrient concentration in specific plant parts during specific growth stages. Nutrient analysis of various tissues in crops is an important way to determine the need for fertilizer that is critical for yield and quality production. Plants analysis is commonly done by chemical method. It has been used as a standard method to diagnosis of mineral deficiency, toxicity and imbalance of nutrients in the plant with highly accurate results. There are some limitations of the chemical methods. It requires large amount of sample and complicated sample preparation involves of hazarded chemicals and is time consuming method.

\section{B. Synchrotron Radiation X-ray Fluorescence; XRF}

A technique used to analyze the composition of elements within the sample. The X-rays fluorescent caused by the electrons of outside layer that replaces the inside layer electron that dropped out. The dropped out of the inner layer electrons caused by the atomic were stimulated by various kinds of energy such as high energy particles, gamma rays or X-rays. These energy are greater than the binding energy of the electrons in it layer. When the electron removed from power layer, it causes a space and the electrons of higher energy level fall into this space and emitted energy in the X-rays radiation form. Energy ejected of atomic is equal to the difference between the energy of electrons in original layer and energy of electron replaced. Because atomic types and arrangement of power in layer are different, it has the energy that is different according to type of atom. If the energy ejected from the atom can be detected, the atomic type in the sample can also be identified. 
The X-rays fluorescent technique is a non-destructive sample method, it requires small amount of samples and the sample preparation is not complicated. It can be used to analyze the sample in almost any form (metal, ceramics, rubber, plastics, liquid, viscous materials, oil, organisms sample such as plant parts). In addition, it can determine the distribution of elements in the sample materials. The limitation of this technique is that it is unable to analyze low atomic number elements such as carbon, hydrogen, oxygen and nitrogen.

The X-ray fluorescence technique was successfully used to characterize the chemical composition of the feldspar by detecting silica, titanium dioxide, alumina, ferric oxide, magnesium oxide, calcium oxide, sodium oxide and potassium oxide [5]. Study of macronutrients and micronutrients in soils developed from the basalt stone in the Northeast of Thailand by XRF machine found the distribution pattern of aluminum, silicon and iron [6]. The application of synchrotron XRF technique to determine the minerals distribution in various parts of the spinach showed that the elements concentrations in the roots was higher than leaves and stems and the base of root had a higher mineral content than at the root tip, potassium, calcium, iron, nickel and zinc content were very high in the base of stem and most of elements accumulated around the midrib and the central area of leaves [7]. In 2001, XRF was used to monitor heavy metals in plants vascular that grow in the reservoir and the results were compared to atomic absorption spectroscopy (AAS) method, the result showed that copper and cobalt content determined by XRF was consistent with AAS, but zinc and nickel contents were different between the two methods [8].

\section{MATERIAL AND METHODS}

The pot experiment was conducted under green house conditions at Suranaree University of Technology, Nakhon Ratchasima, Thailand in 2013. The experimental design was randomized complete block design (RCBD) with 3 replications. Seven methods of irrigation and fertilizer applications were applied to grape variety Marroo Seedless. They consisted of T1) control (no fertilizer), T2) surface irrigation + solid application of 12-24-12 $\mathrm{N}-\mathrm{P}_{2} \mathrm{O}_{5}-\mathrm{K}_{2} \mathrm{O} \mathrm{kg} / \mathrm{rai}$, T3) drip irrigation + solid application of 12-24-12, T4) fertigation of 12-24-12, T5) fertigation of 10.2-4.2-17.9, T6) fertigation of 10.2-4.2-17.9 + secondary nutrients and T7) fertigation of 10.2-4.2-17.9 + secondary nutrients + micronutrients. Fresh leaves from upper, middle and lower parts of the stem were collected at 30 day after fertilizer application in all treatments (Fig. 1). Two different position areas of the leaves were selected (Fig 2) for nutrient analysis by chemical technique. The samples were digested with $\mathrm{HNO}_{3}+\mathrm{HClO}_{4}$. P was analyzed by Vanadomolybdate method [9], potassium and calcium were determined with Atomic Absorption Spectrophotometer (AAS) [10].

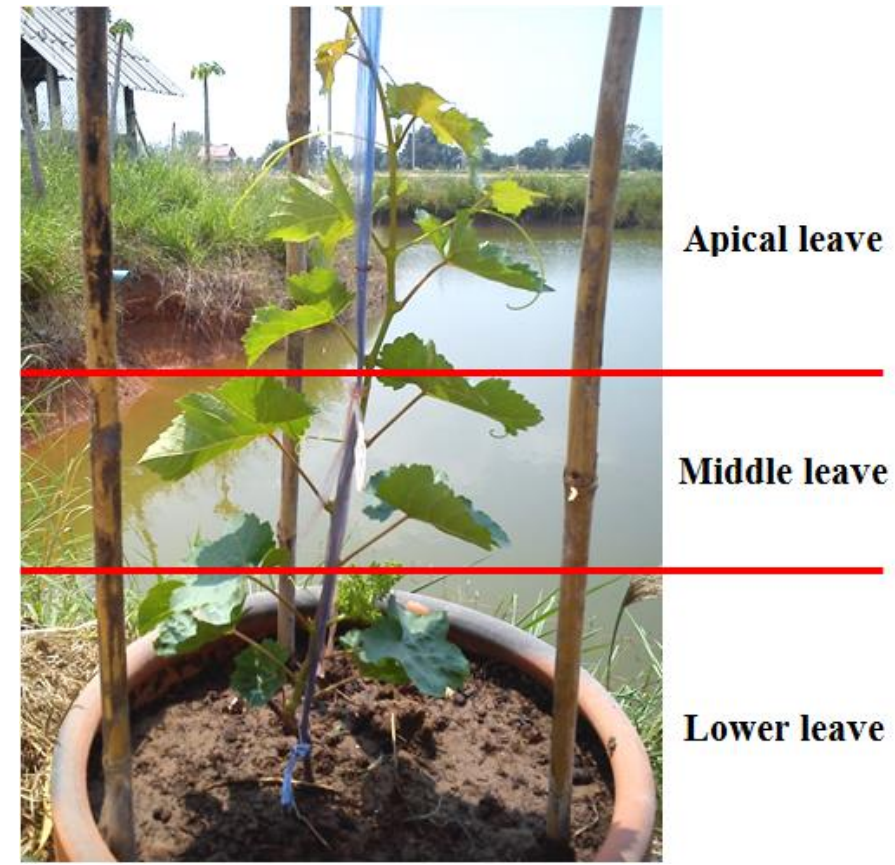

Fig. 1: Segmentation of the grape leaves for plant nutrients

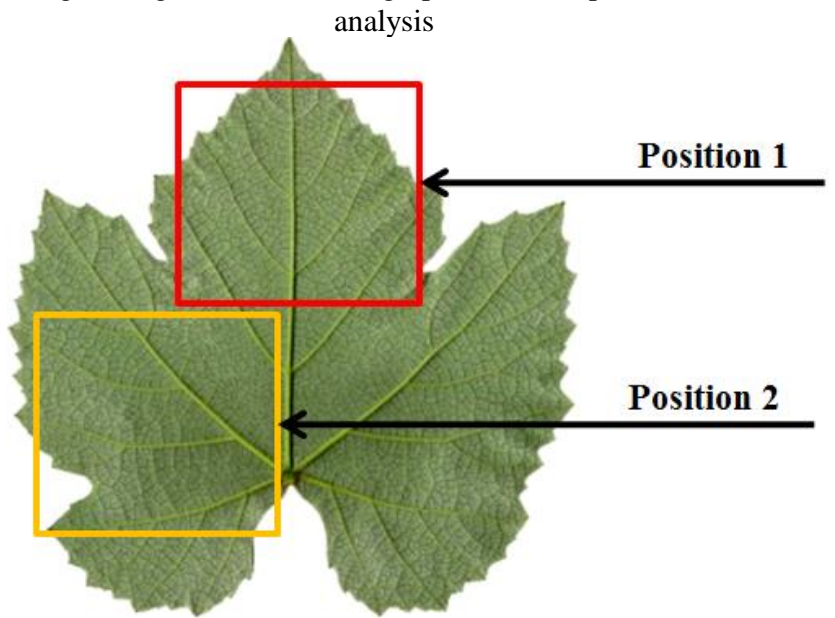

Fig. 2: The areas for plant nutrients analysis by chemical and XRF technique on grape leaves

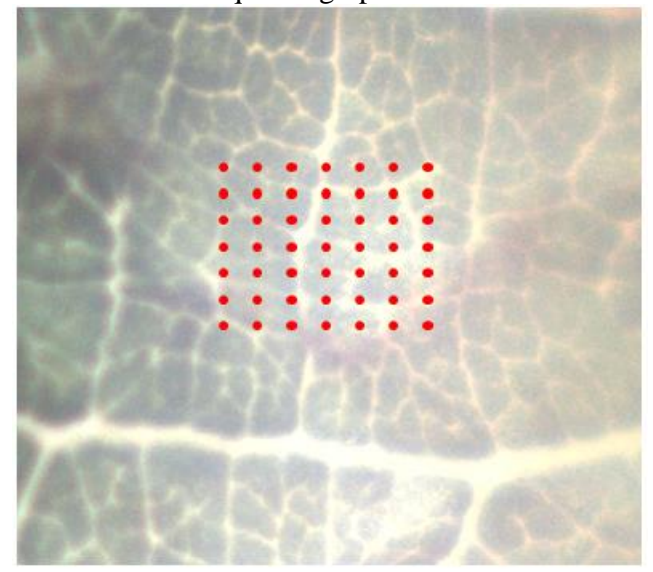

Fig. 3: Marking points on grape leaves sample for analysis by XRF technique

All leaf samples from the different parts of the stem were analyzed for $\mathrm{P}, \mathrm{K}$ and $\mathrm{Ca}$ by XRF technique. The leaves were cleaned with deionized water and were placed on the sample holder for nutrients analysis by X-rays fluorescence from a 
synchrotron light source in two different positions (Fig. 2). In each position, 49 points were determined for $\mathrm{P}, \mathrm{K}$ and $\mathrm{Ca}$ (seven rows and seven points in each row, with $0.5 \mathrm{~mm}$. spacing between points) (Fig. 3). The analysis duration was 30 second per point. The data was analyzed by pyMCA [11].

\section{RESULTS AND DISCUSSION}

\section{A. Chemical analysis}

Chemical analysis of leaf nutrients (TABLE I) showed high variation of nutrient content between treatments. $\mathrm{P}, \mathrm{K}$ and $\mathrm{Ca}$ were lowest $(0.196 \%, 1.431 \%$ and $0.113 \%)$ in the control. P was highest in T3 $(0.525 \%)$, while $\mathrm{K}$ was highest in T3, T6 and $\mathrm{T} 7(1.737 \%, 1.715 \%$ and $1.790 \%)$ and $\mathrm{Ca}$ was highest in T6 and T7 $(0.266 \%$ and $0.260 \%)$. Comparison of nutrients accumulation with optimum nutrients in leaves grape found that $\mathrm{P}$ was in the optimal range in all treatments except the control; $\mathrm{K}$ was in the optimal range or higher, while $\mathrm{Ca}$ levels were lower than the optimal range in all treatment except T6 and $\mathrm{T} 7$.

$\mathrm{P}, \mathrm{K}$ and $\mathrm{Ca}$ contents were significantly different between leaves from different parts of the stem. P content was highest in the middle leaves $(0.398 \%)$ and lowest in the lower leaves $(0.321 \%)$. K was highest in the middle leaves $(1.672 \%)$ and lowest in the apical leaves $(1.518 \%)$, while $\mathrm{Ca}$ was highest in the apical leaves $(0.204 \%)$ and lowest in the lower leaves $(0.132 \%)$. All nutrient contents $(\mathrm{P}, \mathrm{K}$ and $\mathrm{Ca})$ were not significantly different between the two selected positions of the leaves. (TABLE I).

TABLE I

NUTRIENT CONTENT IN GRAPE LEAVES ANALYZED BY CHEMICAL TECHNIQUE.

\begin{tabular}{|c|c|c|c|}
\hline \multirow{2}{*}{ Treatments } & \multicolumn{3}{|c|}{ Percentage (\%) } \\
\hline & $\mathbf{P}$ & $\mathbf{K}$ & Ca \\
\hline T1, Control (no fertilizer) & $0.196 \mathrm{f}^{1}$ & $1.431 \mathrm{c}$ & $0.113 c$ \\
\hline T2, Surface Irrigation + solid application $12-24-12$ & $0.450 \mathrm{~b}$ & $1.480 \mathrm{c}$ & $0.116 \mathrm{c}$ \\
\hline T3, Drip Irrigation + solid application $12-24-12$ & $0.525 \mathrm{a}$ & $1.737 \mathrm{a}$ & $0.133 \mathrm{c}$ \\
\hline T4, Fertigation $+12-24-12$ & $0.403 \mathrm{c}$ & $1.572 \mathrm{~b}$ & $0.133 \mathrm{c}$ \\
\hline T5, Fertigation $+10.2-4.2-17.9$ & $0.271 \mathrm{e}$ & $1.493 \mathrm{c}$ & $0.172 \mathrm{~b}$ \\
\hline T6, Fertigation $+10 \cdot 2-4 \cdot 2-17.9+$ secondary nutrients & $0.350 \mathrm{~d}$ & $1.715 \mathrm{a}$ & $0.266 \mathrm{a}$ \\
\hline T7, Fertigation $+10.2-4.2-17.9+$ secondary nutrients + micronutrients & $0.312 \mathrm{~d}$ & $1.790 \mathrm{a}$ & $0.260 \mathrm{a}$ \\
\hline \multicolumn{4}{|l|}{ Segmentation of the grape leaves } \\
\hline Apical leaves & $0.355 \mathrm{~b}$ & $1.518 \mathrm{c}$ & $0.204 \mathrm{a}$ \\
\hline Middle leaves & $0.398 \mathrm{a}$ & $1.672 \mathrm{a}$ & $0.176 \mathrm{~b}$ \\
\hline Lower leaves & $0.321 \mathrm{c}$ & $1.617 \mathrm{~b}$ & $0.132 \mathrm{c}$ \\
\hline \multicolumn{4}{|l|}{ Leave area position } \\
\hline Position 1 & 0.355 & 1.584 & 0.166 \\
\hline Position 2 & 0.361 & 1.621 & 0.175 \\
\hline CV (\%) & 9.3 & 7.1 & 13.6 \\
\hline Optimum nutrients in leaves grape $^{2}$ & $0.21-0.24$ & $1.21-1.40$ & $0.25-0.35$ \\
\hline
\end{tabular}

${ }^{1}$ In a column within each factor, means followed by a common letter are not significantly different at $5 \%$ level by DMRT

${ }^{2}[12]$

\section{B. Synchrotron radiation $X$-ray fluorescence}

The spectrum of $\mathrm{P}, \mathrm{K}$ and $\mathrm{Ca}$ analysis of grape leaves with synchrotron X-ray fluorescence is shown in Fig. 4. The measurement of $\mathrm{X}$-rays reading were count value, the values are qualitative data but proportional to the amount of elements in the samples. The total values (net count) were the sum of the 49 individual points from the area scan.

The analysis results showed that all 3 nutrients $(\mathrm{P}, \mathrm{K}$ and $\mathrm{Ca}$ were highly significant different between treatments (TABLE II). The average net count value of $\mathrm{P}$ was lowest in the control $(1,050)$ and highest in T3 $(1,547)$. Net count of $\mathrm{K}$ was lowest in T5 $(121,105)$ but was not significantly different with T1, T2 and T4 (123,892, 121,905 and 124,719 respectively) and was highest in $\mathrm{T} 7(157,434)$. Net count of $\mathrm{Ca}$ was lowest in T1 $(138,525)$ and highest in T6 $(182,721)$.

$\mathrm{P}, \mathrm{K}$ and $\mathrm{Ca}$ net count were significant different between various parts, net count $\mathrm{P}$ was lowest in apical leaf $(1,083)$, while it was not different between middle leaf and lower leaf (1,395 and 1,394). K net count was not different in all parts of leaves. Ca net count was lowest in lower leaf $(119,329)$ and highest in apical leaves $(174,773)$. Net count of all nutrients were not significant different between position 1 and 2 of the leaves.

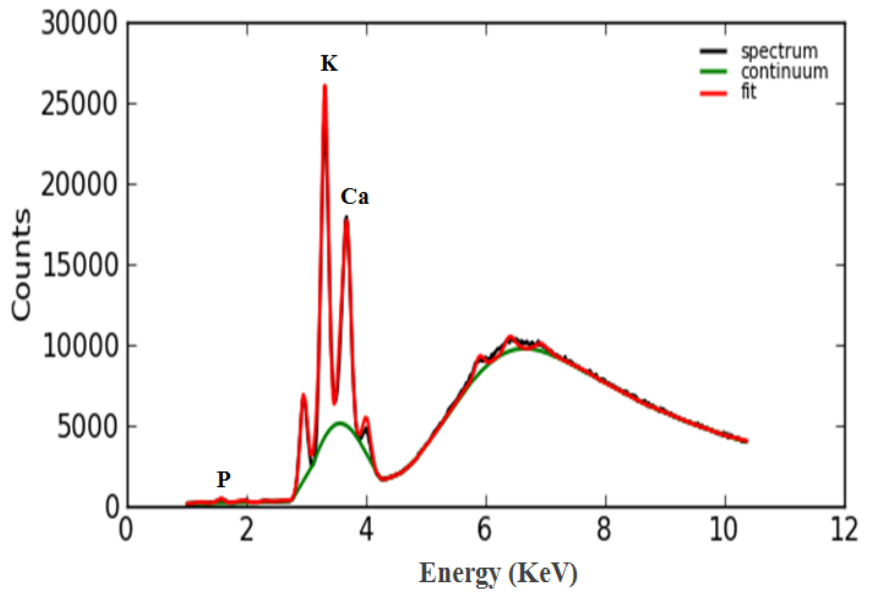

Fig. 4: spectrum of $\mathrm{P}, \mathrm{K}$ and $\mathrm{Ca}$ analysis in grape leave by XRF technique 
TABLE II

RELATIVE INTENSITY OF THE MINERAL ELEMENTS IN THE GRAPE LEAVES ANALYZED BY SYNCHROTRON RADIATION X-RAY FLUORESCENT TECHNIQUE.

\begin{tabular}{|c|c|c|c|}
\hline \multirow{2}{*}{ Treatments } & \multicolumn{3}{|c|}{ Net count } \\
\hline & $\mathbf{P}$ & $\mathbf{K}$ & $\mathbf{C a}$ \\
\hline T1, Control (no fertilizer) & $1,050 \mathrm{~d}^{1}$ & $123,892 b$ & $138,525 \mathrm{c}$ \\
\hline T2, Surface Irrigation + solid application 12-24-12 & $1,469 \mathrm{ab}$ & $121,905 \mathrm{~b}$ & $141,651 \mathrm{c}$ \\
\hline T3, Drip Irrigation + solid application 12-24-12 & $1,547 \mathrm{a}$ & $141,522 \mathrm{ab}$ & $150,039 \mathrm{bc}$ \\
\hline T4, Fertigation $+12-24-12$ & $1,363 b$ & $124,719 b$ & $148,939 b c$ \\
\hline T5, Fertigation $+10.2-4.2-17.9$ & $1,121 \mathrm{~d}$ & $121,105 b$ & $150,460 \mathrm{bc}$ \\
\hline T6, Fertigation + 10.2-4.2-17.9+ secondary nutrients & $1,327 \mathrm{bc}$ & $140,054 \mathrm{ab}$ & $182,721 \mathrm{a}$ \\
\hline $\mathrm{T} 7$, Fertigation $+10.2-4.2-17.9+$ secondary nutrients + micronutrients & $1,159 \mathrm{~cd}$ & $157,434 \mathrm{a}$ & $172,089 \mathrm{ab}$ \\
\hline \multicolumn{4}{|l|}{$\begin{array}{l}\text { Segmentation of the leaves } \\
\end{array}$} \\
\hline Apical leaves & $1,083 b$ & 136,978 & $174,773 \mathrm{a}$ \\
\hline Middle leaves & $1,395 \mathrm{a}$ & 137,692 & $170,651 \mathrm{a}$ \\
\hline Lower leaves & $1,394 \mathrm{a}$ & 124,172 & $119,329 b$ \\
\hline \multicolumn{4}{|l|}{ Leave positions } \\
\hline Position 1 & 1,293 & 130,807 & 150,857 \\
\hline Position 2 & 1,288 & 135,087 & 158,978 \\
\hline $\mathrm{CV}(\%)$ & 10.0 & 12.6 & 11.4 \\
\hline
\end{tabular}

${ }^{1}$ In a column within each factor, means followed by a common letter are not significantly different at $5 \%$ level by DMRT

\section{Regression analysis}

Regression analysis of $\mathrm{P}, \mathrm{K}$ and $\mathrm{Ca}$ between chemical and synchrotron radiation $\mathrm{X}$-ray fluorescence technique were shown in Fig 56 and 7. There were highly significant positive correlations between leaf nutrient analyzed by chemical method and XRF technique.

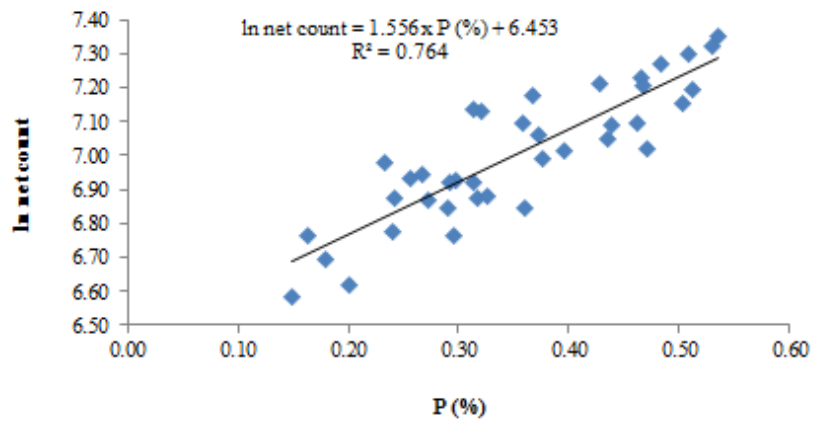

Fig. 5: The regression and correlation of $\mathrm{P}$ between chemical and XRF

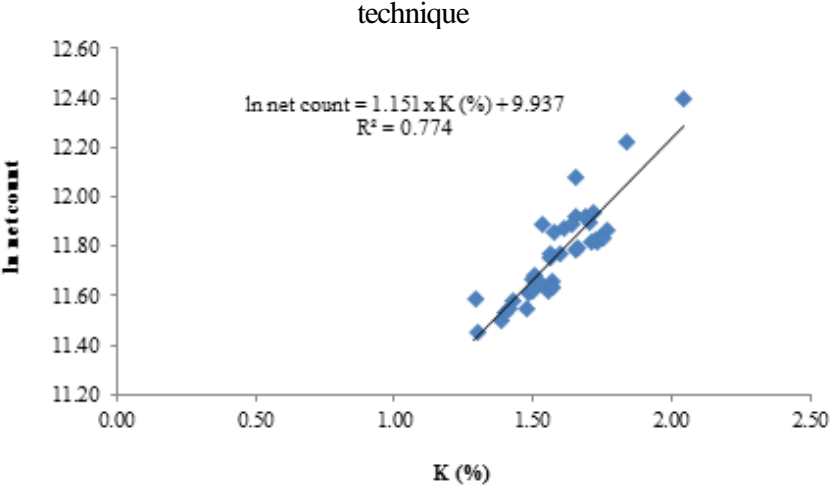

Fig. 6: The regression and correlation of $\mathrm{K}$ between chemical and XRF technique

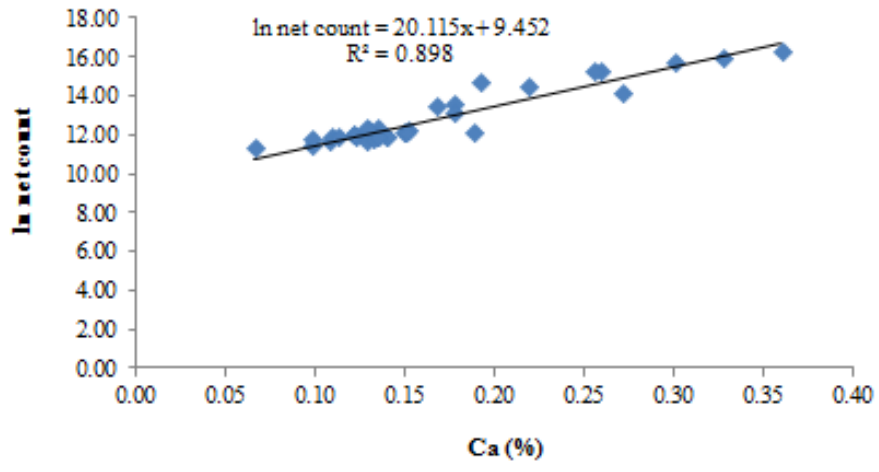

Fig. 7: The regression and correlation of Ca between chemical and XRF technique

\section{CONCLUSION}

The results reviewed that the Synchrotron XRF technique provided results of leaf nutrient analysis with a similar trend as chemical analysis. The regression and correlation analysis indicated the significantly positive correlation of the plant nutrient contents $(\mathrm{P}, \mathrm{K}$ and $\mathrm{Ca}$ ) between the synchrotron XRF technique and the chemical method $\left(\mathrm{R}^{2}=0.76,0.77\right.$ and 0.90$)$. Furthermore XRF technique has several advantages over the chemical method such as its non-destructive sample method, small amount of sample requirement and simple sample preparation. This suggested that XRF technique could be an alternative method for nutrient analysis and the diagnosis of nutrient status in grape.

\section{ACKNOWLEDGMENT}

This work was supported by Suranaree University of Technology Research Fund and National Research Council of Thailand.

\section{REFERENCES}

[1] D. Imed. (November 2012). Grape Petiole Analysis. (n.d.). Department of Horticulture and Crop Science OARDC, the Ohio State University. [On-line]. Available: http://ohiograpeweb.cfaes.ohio-state.edu/

[2] Grapevine nutrition. (November 2012). Petiole analysis. vitinotes. [Online]. Available: www.crcv.com.au 
[3] Bunch Grape Nutrition Management. (November 2012). [On-line]. Available:http://www.smallfruits.org/BunchGrapes/production/TissueA nalysisforGrapevines.pdf.

[4] S. Tancharakorn, W. Tanthanuch, N. Kamonsutthipaijit, N. Wongprachanukul, M. Sophon, S.Chaichuay, C. Uthaisarand and R. Yimnirun, "The first microbeam synchrotron X-ray fluorescence beamline at the Siam Photon Laboratory" J. Synchrotron Rad, vol 19, pp. 536-540, 2012.

[5] B. Thacom, "Properties and Parametric Analyses of Feldspar Flotation by Column Cell Technique," M.S. thesis, Dept. Mining. Eng., Chang Mai Univ., 2008

[6] S. Thanachit, A. Suddhiprakarn, I. Kheoruenromne and R. J. Gilkes, "Major and Trace Elements in Basaltic Soils in Northeast Thailand," in Proc. 44th Kasetsart University Annual Conf., 2006, pp. 161-169.

[7] S. Z. Xin, Y. J. Song, C. Lv, Y. K. Rui, F. S. Zhang, W. Xu2, D. Wu, S. Wu,J. Zhong, D. L. Chen, Q. Chen1 and F. T. Peng, "Application of synchrotron radiation X-ray fluorescence to investigate the distribution of mineral elements in different organs of greenhouse spinach" HORT. SCI, vol 4, pp. 133-139, 2009.

[8] L.M. Kipriyanova, S.Y. Dvurechenskaya, I.P. Sokolovskaya, V.A Trunova, and G.N. Anoshin, "XRFSR technique in the investigations of elements content in aquatic vascular plants and bottom sediments" Nucl. Instrum. Methods Phys. Res, Vol 470, pp 441-443, 2001. http://dx.doi.org/10.1016/S0168-9002(01)01093-2

[9] P.R. Hesse, Total elemental analysis and some trace elements. A test book of soil chemical analysis, 1971, pp. 371-475.

[10] J. B. Jones, "Laboratory guide for conducting soil tests and plant analysis" CRC Press LLC, Boca Raton, Florida, 2001.

[11] V. A. Sole, E. Papillon, M. Cotte, P. H. Walter and J. Susini, "A multiplatform code for the analysis of energy-dispersive X-ray fluorescence spectra" SPECTROCHIM ACTA B, vol 62, pp. 63-68, 2007. http://dx.doi.org/10.1016/j.sab.2006.12.002

[12] Guide to Creating a vineyard, (1999). School of Biotechnology, Institute of Agricultural Technology, Suranaree University of Technology, Nakhon Ratchasima, 1999, pp. 133. 